Fecha de recepción: abril 2020 Fecha de aceptación: mayo 2020 Versión final: junio 2020

\section{La reconfiguración de los sistemas de la cultura estética y su influencia en la iconografía de la artesanía Salasaca}

Andrea Daniela Larrea Solórzano ${ }^{(1)}$

Resumen: Este análisis surge a partir de una investigación macro que busca determinar de qué manera las transformaciones en los movimientos del arte y el diseño en el Ecuador impulsaron las modificaciones gráficas en las artesanías salasacas durante los años 1960 al 2010. Se trata por tanto de un estudio que busca comprender el proceso de reconfiguración de los sistemas residuales y dominantes, dentro del marco de la cultura estética ecuatoriana, y cómo este proceso transfiguró las características formales y figurativas de la artesanía de este pueblo.

Palabras clave: Iconografía - sistemas estéticos - arte - artesanía - diseño - Salasaca

[Resúmenes en inglés y portugués en la página 93]

(1) Doctora en Diseño, Universidad de Palermo - Argentina. Magister en Docencia Universitaria. Diseñadora Gráfica Publicitaria.

\title{
Introducción
}

En el presente artículo, tomando en cuenta el análisis de los "sistemas culturales" que conforman el campo de la "cultura estética" -desde la argumentación expuesta por Juan Acha (1979, 1981)-, se investigan los cambios en la iconografía salasaca. Estos, en función de las transformaciones que se dieran en los movimientos del arte y el desarrollo del campo del diseño en el Ecuador durante el período comprendido entre los años 1960 al 2010, en vínculo con la producción artesanal del pueblo Salasaca ${ }^{1}$.

En el presente estudio se efectuaron múltiples visitas a la comunidad, donde fue posible entablar diálogos con informantes claves. A través de ellos se estableció una secuencia cronológica de varios acontecimientos durante los cuales los artesanos salasacas desarrollaron su obra junto con artistas plásticos y, posteriormente, con otros profesionales (arquitectos, 
antropólogos y sociólogos), vinculados a la definición del campo del diseño nacional. Como resultado de este trabajo se generó un banco de datos fotográfico desde el cual se desplegó un proceso comparativo entre la producción artesanal y la obra de determinados artistas plásticos. Se dio cuenta, además, de las coincidencias entre las formas de expresión iconográficas frente a ciertos programas metodológicos aplicados a partir de los años 1980, que se sirvieron para consolidar académicamente la disciplina de diseño en el país.

Por lo señalado se deja notar que la técnica fundamental que se utilizó en este estudio fue el análisis de imágenes, mismo que se afianzó por medio del uso de fichas de interpretación de las representaciones visuales salasacas y las obras plásticas definidas. Además, se organizó una matriz comparativa de los rasgos visuales más preponderantes. Por medio de estos recursos fue posible establecer las características visuales fundamentales que permiten reconocer la presencia de los movimientos artísticos y las categorías de diseño en la iconografía salasaca. Estas categorías se hacen evidentes a través de: los tipos de estilización, el carácter bi y tridimensional de las obras, las texturas, la cromática y la línea gráfica. En el marco de la reconfiguración de los sistemas residuales y dominantes de la cultura estética ecuatoriana (es decir, de sus componentes: arte, artesanía y diseño), se identifican las transformaciones formales y figurativas en la iconografía de las artesanías salasacas. Estableciendo que estos cambios se generaron, en primer lugar, por la interacción entre los artesanos del pueblo y determinados artistas. Evidenciando, así, la influencia del arte plástico ecuatoriano en las representaciones visuales, que pueden observarse tanto en la indumentaria como en el tapiz salasaca. En segundo lugar, y concordando con lo antedicho, a partir de 1980 es posible también reconocer sobre estos soportes la presencia del diseño gráfico en su composición.

\section{La interacción entre los sistemas residuales y dominantes de la cultura estética}

Juan Acha $(1979 ; 1981)$ reconoce que los universos culturales existentes están atravesados por prácticas estéticas populares y hegemónicas. Y, es en medio de estas experiencias estéticas que se desarrollan complejos relacionales, internos y externos, que surgen en el proceso sociocultural de producción, distribución y consumo de bienes artísticos. Por lo tanto, los productos que surgen desde el campo del arte están ligados íntimamente con la ciencia y la tecnología; al mismo tiempo dependen de la interacción entre el individuo, la sociedad y la cultura (Acha, 1981).

En su texto, Flores (1988) plantea que, para Acha, las "artesanías, artes y diseños conviven, se retroalimentan, e interactúan, no solo en sus formas específicas, sino, también en sus mismos procesos de producción, distribución y consumo" (Flores, 1988, p.32). Es en este proceso de interrelación, entre los tres campos de producción de bienes artísticos, que, en la contemporaneidad, "los diseños vienen a constituir el verdadero arte de nuestro tiempo desde el punto de vista sociocultural, por llegar a las mayorías demográficas y ser recibido con agrado por estas" (Acha, 1981, p.21). 
Por lo tanto, según el citado autor, las "artes cultas" ${ }^{2}$ y las artesanías se han convertido en los sistemas residuales, mientras que los diseños (desplazando a los anteriores) han pasado a convertirse en el sistema dominante dentro del marco de la cultura estética. No obstante, esto no significa que la relación dialéctica entre los dos sistemas haya dejado de existir. Esto, sin dejar de considerar que las artesanías reflejan sencillez en sus procesos productivos en relación con las artes cultas y los diseños.

Relacionando el concepto de artesanía con otros aspectos en los cuales se desenvuelve, los bienes aquí creados, se incluyen también dentro de las propuestas de folklore. Por lo tanto, son parte de la cultura estética popular, en la cual, los productos de esta estructura cultural se articulan como "objetos (utensilios), imágenes (artesanía), acciones (folklore) y otras manifestaciones de naturaleza intangible" (Acha, 1981, p.25). De este modo, las artesanías, como signo de expresión artística, representan una identidad que es compartida tanto en objetos como en actos humanos. Empero, las artes, estando sometidas a la constante evolución tecnológica, se asocian con las producciones técnicas que dan origen a las propuestas de diseño; por lo tanto, el diseño -desde la arista de su producción- se ha destacado frente a los otros dos campos: arte y artesanía, considerados por el mencionado teórico peruano.

Es en este contexto en el que se desarrolla la producción artesanal del pueblo Salasaca. Considerando, además, que durante el período comprendido entre los años 1960 - 2010, las trasformaciones políticas que se dieran en el Ecuador, al trasladarse de un modelo económico a otro ${ }^{3}$ y al abandonar la condición de estado capitalista con rezagos feudales ${ }^{4}$ para ingresar la totalidad del territorio nacional al modelo capitalista como modo de organización social, dio paso a la puesta en escena de variantes dentro de los movimientos artísticos. Los representantes de estos movimientos reflejaron en sus obras las condiciones políticas y sociales que se vivían en esos momentos. Los continuos cambios políticos, suscitados en el Ecuador, que desencadenaron transformaciones sociales, influenciaron a diversas corrientes artísticas preponderantes, en su mayoría, con visiones críticas, sobre el desenvolvimiento del país. Varios movimientos, como el indigenismo, el feísmo, el realismo social y otros, convirtieron sus obras en elementos de representación destacados en la cultura visual ecuatoriana.

En esta etapa, adicionalmente, se potencia el desarrollo disciplinar del campo del diseño. Pues, ante el limitado desarrollo económico y productivo que se mostraba en el territorio ecuatoriano hasta la década de los años 70, la producción nacional se va transformando, y poco a poco surge la demanda del diseño (sobre todo gráfico), que finalmente se fortalece como disciplina académica en el año $1984^{5}$. No obstante, es necesario considerar, que, para arribar a este proceso, los gestores de esta consolidación académica y práctica trabajaron recurriendo, como un fuerte soporte de inspiración, a las creaciones artesanales, sobre todo a aquellas generadas por los grupos étnicos que habitan el territorio nacional. De igual manera hicieron uso de las gráficas precolombinas. Estos personeros buscaban potenciar, aunque también utilizar, estos recursos que surgían desde el campo artesanal. 


\section{Los componentes de la cultura estética y su expresión en el diseño salasaca.}

Según lo expresado en la investigación de Rachel Corr y Karen Vieira Powers (2012), dentro del pueblo Salasaca se destacan características disímiles ante los demás grupos étnicos ecuatorianos. Estos rasgos identitarios hacen que sus habitantes se referencien a sí mismos como un pueblo de sangre homogénea (Corr y Powers, 2012). Pues, a pesar de que nuevos grupos culturales y étnicos emergen, formando identidades que parecen estar basadas en vínculos primarios, para los salasacas el uso de los símbolos y prácticas culturales comunes presta credibilidad a la idea de que este ha sido un pueblo que ha impedido permearse por otras prácticas culturales en medio de una constante resistencia política y rechazo cultural. No obstante, este relato que hacia ellos mismos es narrado se opone a la realidad expresada en sus tejidos, bordados y otras representaciones artísticas culturales, como las pinturas de los tambores. En estos soportes se pueden ubicar, cronológicamente, los continuos procesos de intercambio y transculturación entre ellos y otros sectores de la población ecuatoriana, al menos, durante la etapa de estudio establecida en este caso.

Durante esta época, los cambios en las prácticas productivas de la creación artesanal del pueblo Salasaca estuvieron influenciadas (entre otras condicionantes) por el vínculo que mantuvieran con varios artistas plásticos. Además, se destaca la práctica conjunta con organizaciones que trabajaban haciendo uso de la naciente concepción de diseño en el país, como es el caso de los proyectos que realizarían los artesanos, bajo la dirección del Instituto Andino de Artes Populares (IADAP).

Estas variantes, en el modo de representación iconográfico del pueblo Salasaca, se hicieron evidentes a través de la incorporación de nuevos elementos gráficos, sobre todo en el tapiz, objeto que a partir de 1960 se convertiría en referente del arte de este grupo indígena.

La iconografía tradicional salasaca puede ser observada tanto en el tejido de sus fajas, en los bordados de su indumentaria y en la pintura de sus tambores. También, durante los primeros años del desarrollo del tapiz (a fines de la década de los 50's y los primeros años de la década de los 60's) se transpusieron las representaciones visuales tradicionales a este soporte textil.

Cuando nos referimos a la estética tradicional de este pueblo consideramos que las figuraciones presentes en las fajas son más geométricas, basadas en planos opuestos y casi con ausencia de líneas curvas; mientras que, en los bordados y en la pintura de los tambores los trazos son más libres y las formas orgánicas.

Hoffmeyer (1985), en el texto Diseños Salasacas señaló algunas características de la estética tradicional que se había consolidado para ese momento en este sector. Aunque, ya en los bordados era posible apreciar representaciones de los procesos de transculturación que se habían atravesado. Hoffmeyer describe a la iconografía del pueblo en los siguientes términos:

(...) las figuras nunca intentan ser naturalistas, sino representan grados de estilizaciones e interpretaciones espaciales. Siempre se presentan los motivos de perfil y con carácter bidimensional, es decir que no se trata de dar una idea de volumen de las figuras (...) No se representa la fisionomía auténtica que tiene un motivo, porque lo que importa es la idea sobre el motivo (Hoffmeyer, 1985, s/p). 

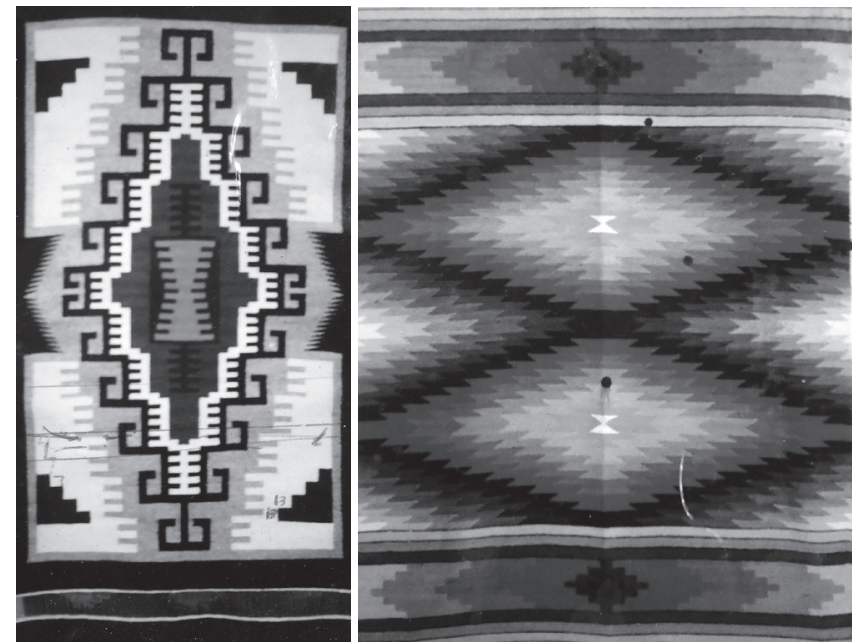

Figuras 1 y 2. Tapices Salasacas con representaciones del arte de los pueblos Navajo. Archivo elaborado por la investigadora.

Durante la segunda mitad del siglo XX el tapiz salasaca se convirtió en un producto artesanal/ comercial que permitió que los tejedores del pueblo fueran reconocidos. Sin embargo, Scheller (1972) y Hoffmeyer (1985) señalarían que los motivos tradicionales del pueblo no se encontraban expuestos en este soporte, ratificando que las formas de representación visual más antiguas del pueblo eran tejidas en las fajas o bordadas en su indumentaria ritual y festiva.

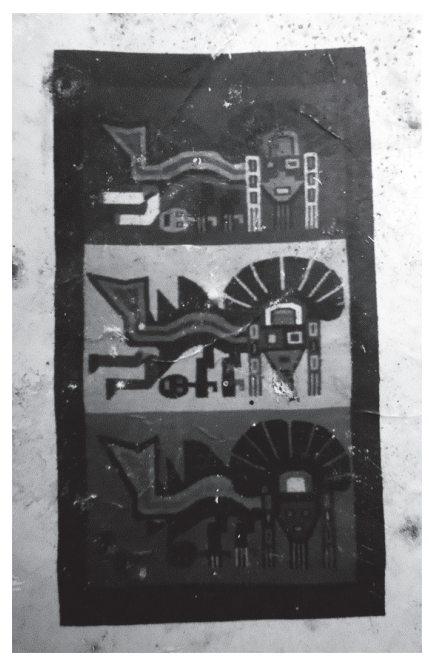

Figuras 3. Tapiz Salasaca, representación de motivos de la Cultura Paracas de Perú. Archivo elaborado por la investigadora. 


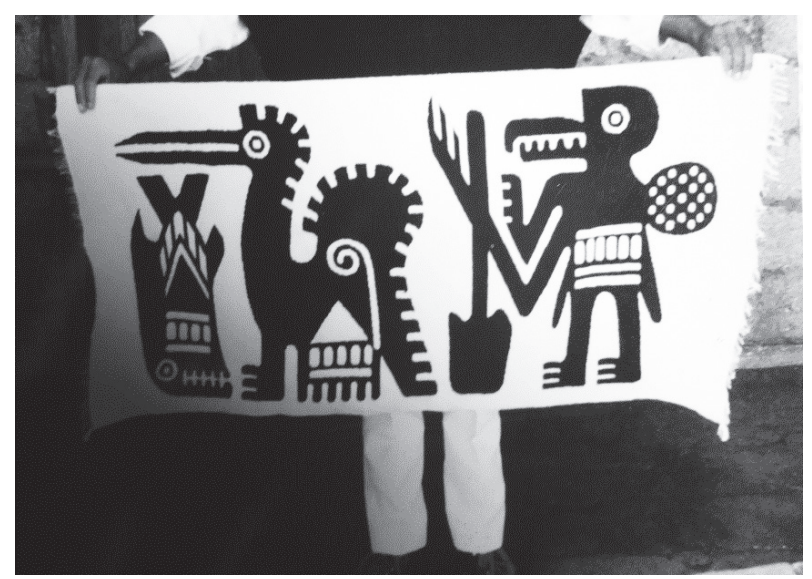

Figura 4. Tapiz Salasaca elaborado en base a gráficas Precolombinas. Archivo CURINDI.

Frente a los cambios sociales, previamente expuestos, y el vínculo con grupos de artistas nacionales y extranjeros, la iconografía salasaca comienza a variar, principalmente la representada en tapiz.

Es así que durante este período es posible encontrar propuestas que van desde: la incorporación de motivos pertenecientes a los pueblos Navajos de Norte América (figuras 1 y 2); la reapropiación de motivos ancestrales andinos, sobre todo aquellos que se identifican con el imperio Inca (figura 3); adicionalmente se considera la inclusión de motivos elaborados por las culturas Precolombinas que estuvieron asentadas en el actual territorio ecuatoriano (figura 4); así como el reconocimiento de elementos asociados al campo del diseño en su composición.

\section{Los expresionismos, la abstracción y las estructuras primarias presentes en la iconografía de la artesanía salasaca.}

En el año 2015 los investigadores Christian Pérez-Avilés y Martha Rizzo-González desarrollaron un análisis que abordaba las construcciones artísticas más relevantes de las artes visuales en el Ecuador a partir de la segunda mitad del siglo XX. Como conclusión, los autores lograron distinguir diez tendencias representativas que, en el caso ecuatoriano, consolidaron las propuestas artísticas de la época. De este modo, figuran en su análisis movimientos tales como: el Realismo Social, el Naturalismo, el Expresionismo, el Informalismo, el Formalismo, el Feísmo, el Magicismo, el Conceptualismo, el Nuevo Expresionismo y el Constructivismo. Estas etapas, adicionalmente, permitieron gestar las obras del Arte Contemporáneo en el Ecuador. 
La observación de estas tendencias establecidas en Ecuador, similares a las desarrolladas en Latinoamérica, en las cuales el arte de los pueblos originarios se fusionó con las manifestaciones que habían llegado al territorio fruto de los procesos de conquistas, lo cual permitió el surgimiento de obras híbridas entre la cosmovisión indígena y la cultura europea, tendencia que estaría presente en la producción artística de nuestro continente durante siglos. En el Ecuador se reflejaría aún esta influencia durante la segunda mitad del siglo $\mathrm{XX}$, cuando las vanguardias locales se hicieron presentes, forjando transformaciones que se basaban en la mentalidad innovadora de varios artistas tales como Eduardo Kingman u Oswaldo Guayasamín quienes proponían estilos que en el principio no serían aceptados. Pérez y Rizzo (2015) consideran, sin embargo, que, en la actualidad, las representaciones artísticas aún se encuentran permeadas por los planteamientos generados en el siglo XX, fundamentalmente en los años 50, 60 y 70. Esto puede evidenciarse en la vigencia y el reconocimiento de las obras en las que los artistas volcaron sus intereses hacia la realidad social y lo autóctono. Este proceso generó el nacimiento de las propuestas ecuatorianas que buscaban el desarrollo de una iconografía propia.

Aunque se propendía a la búsqueda de estilos propios (fenómeno que rindiera sus frutos en el siglo XXI), es interesante destacar que, a pesar del paso del tiempo, las nuevas propuestas que se fueran desarrollando no lograron tener el impacto necesario en la memoria de los observadores, ni de los productores. Se generó, así, "una especie de letargo visual o estancamiento" que ha llevado a la constante repetición en el uso de símbolos y tendencias que, a visión de los autores citados, frenó "el desarrollo de la memoria visual del Ecuador" (Pérez y Rizzo, 2015, p.141).

A nivel global, Guasch (1997) ha realizado revisiones sobre las corrientes artísticas que estuvieron vigentes en sectores geográficos considerados referentes ${ }^{6}$ para el desarrollo del arte culto (tales como Estados Unidos o varios países de Europa). A partir de los años 50 del pasado siglo se destacan las propuestas enarboladas por los seguidores del Expresionismo Abstracto, el Informalismo, el Pop, el Neodadá, el Nuevo Realismo, el Arte Óptico y Cinético, las tendencias Constructivistas; las estructuras primarias como el Minimalismo, lo Conceptual, los Realismos radicales; las intervenciones que toman como soporte artístico al cuerpo, el paisaje y los objetos; así como el florecimiento de la Multidiversidad y el Multiculturalismo. Que lograrían constituirse en los principales referentes del arte a nivel mundial hasta finales del siglo XX.

Los ejemplos citados sobre las corrientes artísticas a nivel mundial (en correlación con lo acontecido durante el mismo período de tiempo en el caso ecuatoriano) representan lo que sucedía durante esta etapa con las llamadas artes cultas. Desde la división de los sistemas estéticos, que presenta Acha, estas artes constituyen, junto a las artesanías, un sistema estético residual. Ante este vínculo se puede comprender por qué en un momento determinado, sus formas de producción se enlazaron.

Es necesario establecer este recorrido sobre la secuencia que tuvieron los movimientos y corrientes de las artes plásticas, pues es posible observar que, en el campo artístico ecuatoriano, varios de estos movimientos globales también tuvieron representantes que generaron sus obras bajo las características gráficas definidas por el mercado global. Mientras esto sucedía en el campo de las artes cultas, en Salasaca los artesanos, asumiendo la guía planteada por 
una serie de proyectos, encabezados por instituciones como la Casa de la Cultura Ecuatoriana (CCE) o el Instituto Andino de Artes Populares (IADAP), participaron de talleres orientados a mejorar su trabajo productivo. En estos talleres formativos, quienes cumplieron el papel de capacitadores fueron principalmente artistas plásticos y arquitectos, los cuales trasladaron las influencias que eran parte del mundo del arte hacia el tejido.

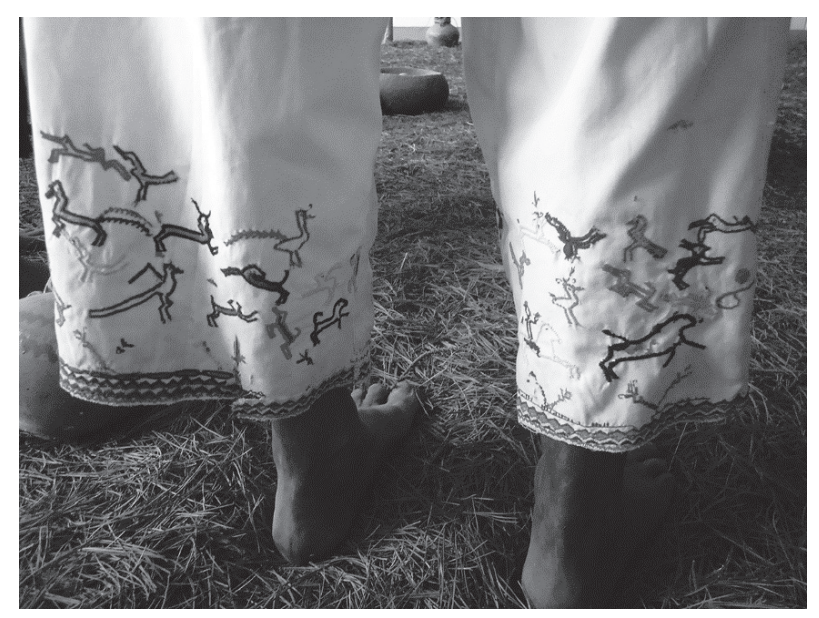

Figura 5. Calzón masculino bordado con motivos tradicionales salasacas. Archivo elaborado por la investigadora.

Es posible evidenciar estas influencias cuando se comparan cronológicamente los modelos de tapiz realizados por los artesanos de este sector. Rasgos básicos, sobre todo de las corrientes asociadas al Realismo Social, el Expresionismo, el Magicismo y el Constructivismo pueden verse sobre estos soportes. Gradualmente las formas de representación autóctonas que estaban expresadas sobre todo en las fajas y en los bordes de los calzones masculinos (figura 5), y que inicialmente se representaban también en los tapices, poco a poco van abandonando la base geométrica y modular que los contenía para ir asumiendo mayor cantidad de formas orgánicas.

Por eso, es necesario, reconocer, brevemente, las características gráficas más representativas de aquellos movimientos artísticos que dejan notar su influencia sobre el tejido del pueblo Salasaca. Se abordan los siguientes, acogiendo la descripción realizada por Pérez y Rizzo (2015, p. 143-144):

\section{- Realismo Social}

Tendencia que asume los rasgos del Muralismo Mexicano desarrollado entre los años 1930 y 1940. 


\begin{abstract}
- Naturalismo
Se origina con base en el Realismo Social. Se exploran múltiples posibilidades que les permitan retratar el contexto social circundante, tomando como antecedente el naturalismo que se aplicaba en Francia. Bajo este fundamento se desplegaron obras que abarcan conflictos sociales, incluyendo el alcoholismo, la prostitución, la violencia y la pobreza. En el Ecuador de modo concreto esta tendencia sería llamada Indigenismo ${ }^{7}$
\end{abstract}

\title{
- Expresionismo
}

Desde la conformación del movimiento artístico conocido como Indigenismo, en el caso ecuatoriano, el expresionismo, se convierte en el eje sobre el cual se establecen las nuevas formas de manifestación. Su desarrollo se sustentó, además, en una fuerte influencia del Expresionismo Alemán. Se buscaba, no solo retratar la realidad, sino, ejercer en las obras cargas emocionales que surgieran desde la exploración interior del artista. Gráficamente se modificaban las formas usando líneas más crudas y colores más puros, buscando mayor dramatismo en las obras.

\section{- Informalismo}

Posterior a la etapa descrita, durante la década del 60 crece el movimiento abstracto, que toma como punto de partida el Informalismo Europeo, que en el caso Latinoamericano se conocería como Ancestralismo. El informalismo permitió a los artistas asumir influencias externas, pero, aterrizándolas exitosamente en la realidad ecuatoriana basándose en el análisis de las propuestas artísticas ancestrales de las culturas precolombinas.

\section{- Formalismo}

Aunque durante un periodo largo el arte ecuatoriano estuvo enmarcado en el tratamiento de temas vinculados a aspectos éticos, y dirigido hacia la crítica social, paulatinamente los autores transformaron sus formas de representación, acogiendo bases compositivas que marcaban la estructura de las obras en función de elementos geométricos y guardando miradas constructivistas.

\section{- Magicismo}

Para la década de los 80 , en oposición a lo retratado por los artistas que se inscribían dentro del movimiento del "Feísmo", se origina el trabajo reaccionario de quienes se guían por el movimiento Surrealista y encuentran en cuestiones mágicas su forma de expresión. Los artistas de este movimiento buscaban la perfección estética en cuanto al ritmo, el color y la composición, buscando devolver "al arte su característica estética".

\section{- Constructivismo}

En base a lo planteado por la abstracción geométrica, un colectivo de artistas considera como lo fundamental para el desarrollo de sus obras a las formas 
arquitectónicas, los recursos matemáticos, planos vectoriales y las composiciones cambiantes, como el nuevo modo de expresión necesario para la representación artística. Este movimiento no solo asume las propuestas vinculadas a las artes plásticas, sino también aquellas que surgen desde el campo del diseño.

Lo antedicho corresponde a la descripción de algunos de los movimientos artísticos que se desarrollaron en el Ecuador desde los años 50 hasta finales del siglo XX, cuyas características visuales básicas son evidentes en las producciones artesanales salasacas.

Como se señaló los motivos gráficos considerados autóctonos del pueblo son aquellos que se encuentran presentes en los bordados y tejidos de su indumentaria. No obstante, desde la introducción en el pueblo de una nueva forma de tejido comercial bajo el uso del telar europeo (a finales de 1950), las representaciones gráficas salasacas también se fueron transformando paulatinamente. Se considera que una de las variables que influyeron en esta transformación fue el contacto que tuvieron los artesanos con artistas plásticos nacionales e internacionales. De forma directa este contacto se dio por medio de talleres de capacitación; y de forma indirecta, conocieron la obra de artistas extranjeros a través de personajes como los voluntarios de los Cuerpos de Paz de los Estados Unidos.

Es así como, durante esta etapa, por ejemplo, se puede notar que el paisaje empieza a ser uno de los elementos más representados, destacándose sobre todo el paisaje urbano colonial, propio de la capital ecuatoriana y nada relacionado con lo que puede observarse en el pueblo Salasaca (figura 6).

Figura 6. Tapiz Salasaca denominado "Las Casitas Quiteñas" representación elaborada en base a la obra del artista Leonardo Tejada. Archivo Olga Fisch Folcklore.

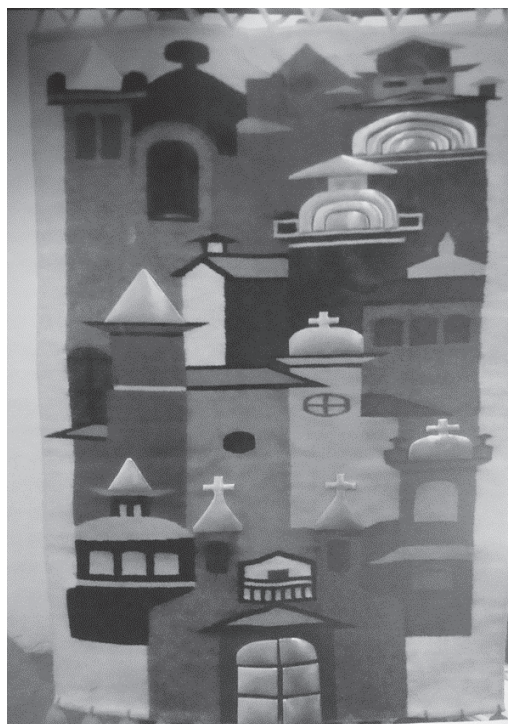


La forma de expresión gráfica cambia desde la representación de un único elemento central hasta la composición de historias narradas por varios elementos dentro de un mismo tapiz. La paleta cromática, que inicialmente era limitada hacia las tonalidades rojas, verdes y negras, obtenidas por medio de procesos de extracción de tinturas naturales, se modifica con el uso de nuevos materiales, el uso de las anilinas específicamente, para el teñido de las lanas, lo cual abre además una nueva posibilidad de expresión, que permite incluso lograr que muchas de las composiciones expresadas en el tapiz sean verdaderas representaciones del Pop Art.

En este caso concreto, es necesario señalar, que la influencia del Pop Art en la producción de la artesanía salasaca está ligada al trabajo específico que los tejedores de este sector realizaron junto al artista Peter Mussfeldt. Este artista y diseñador (alemán- ecuatoriano) trasladó parte de su obra al tapiz; y a partir del conocimiento de la obra específica de este artista, los tejedores asumirían la paleta cromática que Mussfeldt utilizó en su obra durante los años 1970. Esta definición cromática presentaba marcados contrastes, similares a los utilizados por el movimiento Pop (figura 7).

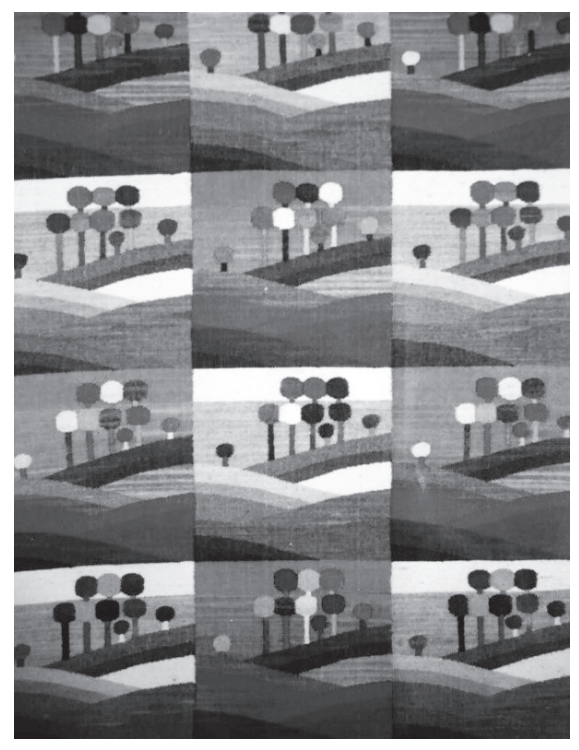

Figuras 7. Tapiz Salasaca elaborado en base a la obra del artista Peter Mussfeldt. Archivo CURINDI.

Se debe considerar además que, a partir de los años 90, corrientes artísticas definidas como la Multidiversidad y el Multiculturalismo, originadas en las propuestas del arte culto, buscaban superar las barreras hegemónicas del arte que limitaban la participación de las propuestas artísticas surgidas en los países considerados del Tercer Mundo. Este movimiento se desarrolló a través de la unificación en varias exposiciones de las propuestas del 
arte contemporáneo occidental y de las áreas culturales periféricas. Jean Huber Martín ${ }^{9}$ (1989), al analizar la muestra francesa pionera denominada Magiciens de la terre, señala que: "La pretensión era pues plantear el concepto de aldea global del arte, en la que lo occidental no compitiera y menos aún fuese modelo, sino simplemente "cohabitara" con el arte de otras culturas definidas desde Occidente en términos de su otredad" (Martín, 198, citado en Guasch, 1997, p.397).

Anna Maria Guasch señala que estos movimientos denominados "Multidiversos" buscaban la "descentralización del arte", la "desmitificación de los juicios de valores formalistas occidentales y de reconocimiento de las cuestiones de alteridad y de multiculturalismo" (Guasch, 1997, p. 398-399); este proyecto ganó mayor fuerza a partir de 1992 bajo la aplicación de tres líneas de trabajo: la inclusión de artistas del Tercer Mundo en los mercados artísticos globales, la presentación de exposiciones colectivas similares a la presentada en París y la difusión internacional del arte contemporáneo de África, Australia y Latinoamérica.

Esta nueva visión del arte, que surgió desde los principales centros de mercadeo de estos productos, volcó la mirada de los artistas de estos sectores hacia la periferia, y buscaban cada vez más trabajar con estos sectores productores de otras formas de arte, que guardaban según lo establecido por Escobar (2012) "otras estéticas". Estos rasgos estéticos no se ajustaban a los cánones occidentales, pues en estos la forma y la función de los objetos está fusionada en un solo cuerpo artístico.

\section{Los patrones de tejido como expresión del sistema dominante de la cultura estética frente a los modos de representación tradicional andino.}

En el acápite de este análisis, se considera el vínculo de los tejedores salasacas con el IADAP, organización que, a través de sus programas de estudio y articulación del arte con la artesanía en el Ecuador, fueron los gestores de la definición del diseño como arista disciplinar en el país.

Una de las bases conceptuales que el IADAP desarrolló para su trabajo con los sectores artesanales relacionados al campo del diseño, planteaba como objetivos fundamentales "evidenciar al artesano que en su medio dispone de temas de inspiración trascendentes que pueden gestar infinitos diseños", así como, también, "motivar al artesano en la creación original, evitando la copia de temas extraños a su realidad" (IADAP, 1999, p.4 -6). Para canalizar estos objetivos, esta institución estableció como fundamento teórico la definición de un motivo gestor que sería conceptualizado como:

(...) un eje de interés tanto para el productor del diseño, cuanto para la colectividad que lo consume y aprecia. Las formas en el diseño artesanal requieren contenidos trascendentes por lo cual deben tener arraigo en la historia y en el entorno. Motivo gestor es todo acontecimiento, forma, o mensaje que tiene interés para la colectividad de un entorno social y geográfico (IADAP, 1999, p.4). 
La actualización de este plan, en el año 1999, se corresponde con las propuestas que, sobre este tema, ya a inicios de los años 1980, el IADAP utilizó para el trabajo conjunto con los artesanos. En los documentos publicados por el Instituto Andino de Artes Populares entre 1981 y 1982, se relata paso a paso como estaban conformados los programas de Capacitación artesanal, y como entre los participantes se acogió también a los artesanos salasacas. Entre los textos que más destacan por su visión práctica se puede citar a: Conceptos operativos de diseño (Folleto $\mathrm{N}^{\circ} 2$ ) y Estructura de la forma plástica. Estos pueden ser considerados como guías de trabajo que orientaron, en el caso del desarrollo del tapiz salasaca, una nueva forma de composición de los elementos, que estaría marcada por la presencia de conceptos de diseño básico durante esta etapa de producción.

Como es posible apreciar, en las siguientes imágenes (figura 8), factores como repetición, traslación, reflejo, rotación, entre otros conceptos básicos de diseño, están presentes en el tapiz salasaca. En la composición se utiliza además nuevos elementos gráficos que se acogieron fruto del trabajo junto con artistas plásticos. No obstante, se debe tomar en cuenta que esta práctica de diseño, desplegada desde el IADAP, no era ajena a las creaciones ancestrales del pueblo Salasaca, tal como puede demostrase con el análisis de sus chumbis o fajas. En estas piezas de indumentaria, la gráfica expuesta se basa en una estructura geométrica que deviene desde su cosmovisión andina es la base para la composición.

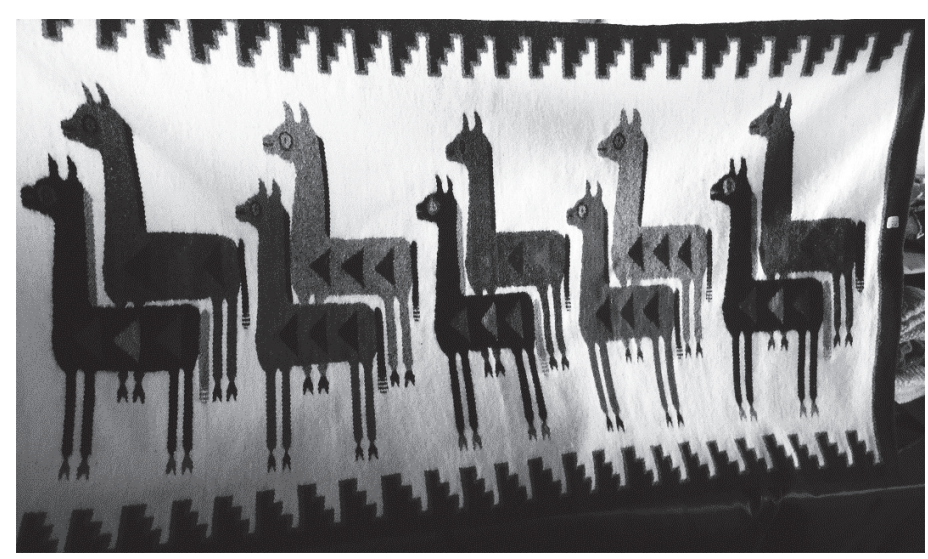

Figura 8. Tapiz Salasaca, representación de camélidos. Archivo CURINDI.

Zadir Milla, por medio de su trabajo "Introducción a la semiótica del Diseño Andino Precolombino" (2008), establece que las composiciones andinas conllevan tres niveles de comprensión; el primer nivel simboliza la Cosmovisión y expresa la convivencia entre el hombre y la naturaleza, y denota por tanto su entorno social. El segundo nivel encarna la Cosmogonía, que pretende explicar el origen de las entidades naturales y sus concepciones 
mágico - religiosas. Finalmente, el tercer nivel atañe a la Cosmología que define la visión del espacio mediante la lógica y las relaciones numéricas.

Por medio de estos niveles es posible comprender la geometría y el simbolismo que guarda la estética andina de las representaciones iconográficas, que además exponen elementos de la filosofía andina (Milla, 2008). Estos modos de representación recurren al uso de elementos discursivos que trasladan mensajes contextuales y significados que son expresados por medio de signos que tienen validez dentro de un espacio definido. En el caso del pueblo Salasaca su visión del mundo se encuentra sobre todo expresada en los tejidos de las chumbis (figura 9).

Figura 9. Muestra de Chumbis con representaciones ornamentales y geométricas. Archivo elaborado por la investigadora.

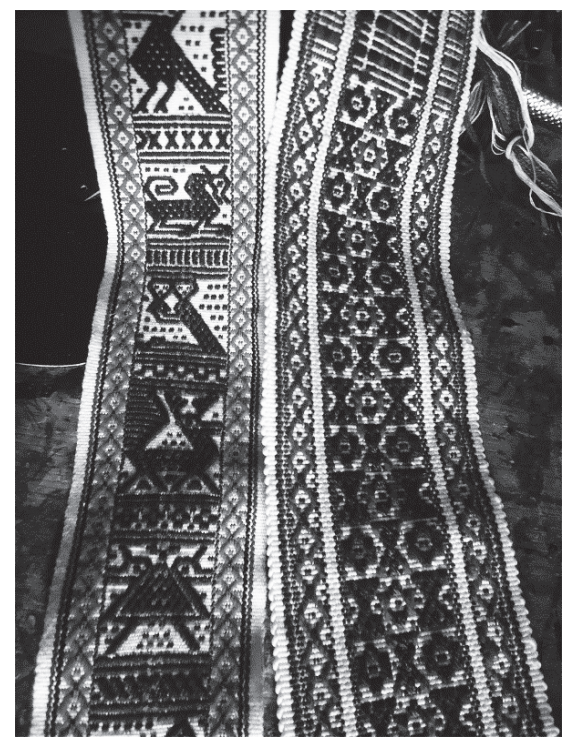

La base de la construcción simbólica andina permite identificar que el sustento de esta construcción es la oposición cromática entre elementos positivos y negativos. Aunque desde el campo del diseño es posible hablar de la presencia de normas de composición visual, en el caso de la simbología andina el concepto base que orienta la forma de distribución de los elementos en el espacio es el Ayllu, considerado como la unidad indivisible señalada en la sociedad andina. En las entrevistas realizadas a diversos informantes claves ellos se refieren al universo simbólico contenido en las fajas. Aunque cada uno de los íconos tejidos posee un mensaje, la descripción total expresado en este elemento solo la conoce el tejedor y la persona que encarga su elaboración. La antropóloga Estelina Quinatoa considera que las fajas conservan mensajes expresados a través de un sistema de helio escritura (Domínguez y Muscico, 2013). 
El concepto de Ayllu utilizado en la composición andina hace referencia además al prójimo, al hermano, es decir al miembro de la comunidad que se solidifica por la participación de sus miembros (Milla Villena, 1992). De acuerdo con la interpretación de Milla Villena (1992) el Ayllu se compone de dos elementos Hanan (alto) y Urin (bajo) que juntos forman dos estructuras básicas primarias llamadas Sayas. Estas Sayas al ser divididas perpendicularmente definen 4 Ayllus (ver figura 10) y como resultado de esta interacción de los opuestos origina un tercer elemento admitido como la unidad.

Sayas

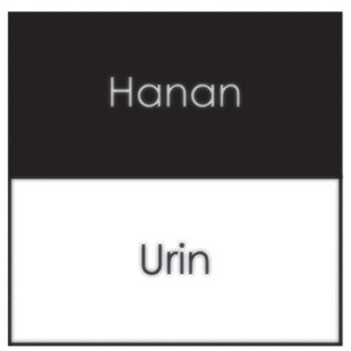

Ayllu

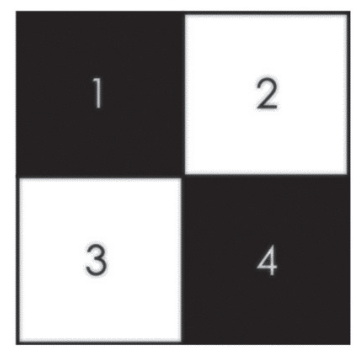

Figura 10. Interpretación de la investigadora.

Si se toma como punto de referencia la geometría armónica que establece el autor peruano Zadir Milla, se identifica además al cuadrado como la base de las modulaciones simétricas estructurales que determinan los procesos formativos de las figuras y de las composiciones simbólicas. El uso del cuadrado determina adicionalmente el concepto de desplazamiento que irradia la relación espacio - tiempo como conjunción cósmica. De este modo, la composición expresada en las representaciones andinas, surge del ordenamiento del espacio y la conjunción de elementos visuales, plásticos y simbólicos (Milla, 2008).

Si estas formas de expresión fueron ya utilizadas por los pobladores de las Culturas Precolombinas Andinas, y su rasgo se ha mantenido por siglos en los grupos étnicos que descienden de este pasado andino, se reconoce que los artesanos salasacas de forma automática incorporan en su práctica cultural estos conceptos. Por esta razón para los salasacas la significación de esta forma de composición se asocia a su cosmovisión, diferente a la expresada como base de las estructuras del diseño.

Durante el proceso de trabajo entre los artesanos salasacas y el IADAP, la estructura que está presente en sus chumbis no había sido trasladada al tapiz. Sin embargo, luego del trabajo conjunto que realizaran, estos elementos vuelven a ponerse en práctica, aunque ahora concibiéndolos como formas de representación de una estructura plástica.

Estos rasgos visuales señalados permiten comprender cómo por un lado se buscó mantener las características de sus representaciones visuales en la indumentaria, mientras que 
las mismas fueron modificadas en el caso del tapiz, expresando variantes tanto formales como figurativas e incluso productivas en su propuesta artesanal. De tal modo que a partir de la década de los 80 y sobre todo en los años 90, el diseño como sistema dominante de la cultura estética ecuatoriana paso a formar parte también del trabajo artesanal salasaca.

\section{Conclusiones}

Frente al análisis de los productos artesanales desarrollados por el pueblo Salasaca podemos señalar que los cambios en la iconografía respondieron a la interacción del grupo indígena con otras culturas visuales. Este fenómeno permitió nuevos procesos de transculturación estética, que reconfiguraron los criterios relacionales (de producción, circulación y consumo) que se expresaron principalmente en los tejidos realizados en este sector. En el Ecuador durante el siglo XX el discurso intelectual y político que mantuvo el desarrollo nacional incluyó a los pueblos indígenas antes desplazados. Este hecho, sin embargo, respondió a la necesidad de demostrar la integración de todo el pueblo ecuatoriano como una visión de progreso con fines turísticos. Mientras tanto la realidad de los pueblos indígenas estaba marcada por la pobreza, el rechazo hacia sus costumbres y una fuerte discriminación. Este discurso de integración nacional, y los conflictos que se vivían durante este período se trasladaron a la práctica artística. En este marco, artistas, arquitectos, antropólogos y otros profesionales afines al campo de las artes retrataron, desde su óptica, las complejas situaciones que atravesaban los grupos indígenas y buscaron, bajo su visión, apoyar el trabajo artesanal de diferentes grupos dentro del país.

En este marco los artesanos salasacas aprendieron una nueva práctica textil, que, si bien nació anclada a fines comerciales se convirtió en una muestra representativa de la habilidad del pueblo. En los tapices se sucedieron diversos momentos estilísticos que evidencian la relación mantenida entre los artesanos con varios sectores.

El proceso de transformación iconográfica que se expresó en el tapiz no solo reveló ciertas coyunturas políticas y sociales del momento, sino que adicionalmente, dejó notar la preponderancia de pensamiento artístico plástico nacional y de ciertas corrientes internacionales. Sin embargo, estos cambios visuales permiten comprender la confluencia permanente entre las fronteras del arte, artesanía y diseño. Estos registros gráficos han posibilitado la lectura de las transformaciones de los productos culturales no solo desde criterios morfológicos y funcionales, sino también relacionales.

El análisis de las trasformaciones a las cuales nos referimos en el presente artículo se ha enfocado sobre todo en el tapiz, no obstante, el estudio de otros productos culturales, como los tambores y los bordados de la indumentaria, es un campo de vacancia que debe ser explorado. En estos dos elementos citados la definición de las formas también estaría asociada a los conceptos del arte occidental, aunque, no de forma específica con los rasgos estilísticos de ciertos movimientos, sino por el contrario a los cambios morfológicos y cromáticos. Estos elementos son más cercanos al diseño, como sistema estético dominante, que, hacia las artes y la propia artesanía, sistemas residuales, que en su momento ejercieron influencia en las modificaciones iconográficas. 


\section{Notas:}

1. El Pueblo kichwa Salasaca conforma uno de los tres grupos étnicos que están ubicados en la provincia de Tungurahua dentro del territorio Ecuatoriano. Es reconocido, principalmente, por el trabajo artesanal textil que se realiza, sobre todo a través de la elaboración de tapices.

2. Juan Acha (en su definición de sistemas culturales estéticos) acoge el uso del término "artes cultas" como una forma de marcar la diferencia que socialmente establecen los sectores de élite entre las artes y las artesanías, estableciendo no solo una demarcación entre las prácticas expresadas en el campo artístico (sean estas la pintura, el dibujo o el grabado) frente al desarrollo de los objetos. Elementos que, siendo artísticos, al unificar la forma estética y la función, se los considera solo como artesanales. Además, la expresión "arte culto" denota una diferencia de estratos sociales, entre quienes son parte del mundo del arte y quienes son parte de las actividades de las artes populares.

3. Los cambios políticos durante esta etapa incluyeron el paso de un régimen dictatorial a uno democrático.

4. Hasta los años 1970 Ecuador estaba constituido por una sociedad semi-feudal y semicolonial que a partir de los años 80 ' dio paso a la definición de un país capitalista atrasado (frente a otros países de América y frente a Europa), con una economía dependiente de los monopolios. "Esta transición se expresó en cambios significativos de la estructura económica y social" (Línea Política PCMLE, 1991, p.27).

5. Se considera esta fecha tomando en cuenta la creación de la primera Facultad de Diseño en Ecuador, en el año de 1984, en la Universidad del Azuay.

6. Desde el punto de vista del mercado artístico global, se consideran como referentes mundiales del arte a los sectores que marcan las tendencias que definen las propuestas artísticas que se convierten en modelos para diversos sectores. El arte occidental ha sido el que permanentemente ha impuesto los cánones aceptados para la producción; los trabajos en este campo se han concentrado sobre todo en Estados Unidos y en Europa, destacándose como capitales artísticas a Francia y Alemania.

7. Dentro de esta tendencia en el caso de la pintura ecuatoriana se destaca ante todo el trabajo de Oswaldo Guayasamin, quien hasta la actualidad es el artista más reconocido de este territorio.

8. Las características estéticas que se buscaba retomar por parte de los pintores del Magicismo ecuatoriano están asociadas al concepto del arte culto, en oposición al reconocimiento de las nuevas propuestas estéticas que se estaba dando en Ecuador, entre las que se incluían las propuestas artísticas de los pueblos originarios y la recuperación de las gráficas Precolombinas.

9. Martin, Jean-Hubert fue comisario de la muestra Magiciens de la terre, celebrada en el Centre Georges Pompidou, Grande Halle de la Villete, Paris, entre el 18 de mayo y el 14 de agosto de 1989. Primera muestra del movimiento Multicultural que buscaba la convivencia entre códigos culturales considerados antes irreconciliables. 


\section{Referencias Bibliográficas:}

Acha, J. (1979). Arte y sociedad Latinoamérica: El sistema de producción. México. Fondo de Cultura Económica.

Acha, J. (1981). Arte y sociedad Latinoamericana: El producto artístico y su estructura. (1º ed.). México. Fondo de Cultura Económica.

Acha, J. (1993). Las culturas estéticas de América Latina (Reflexiones). México: Universidad Nacional Autónoma de México.

Corr, R; Vieira, K. (2012). "'ETHNOGENESIS, ETHNICITY, AND "'CULTURAL REFUSAL The Case of the Salasacas in Highland Ecuador"'. En: Latin American Research Review, Vol. 47, Special Issue

Corr, R; Vieira, K. (2014). “ ¿Trasplantes incaicos o etnogénesis poscolonial? El origen de los Salasacas de la Sierra ecuatoriana”. En: Procesos Revista Ecuatoriana de Historia $n .^{\circ} 40$.

Escobar, T. (2012). La belleza de los otros. ( $2^{\circ}$ ed.). La Habana. Fondo Editorial Casa de las Américas.

Escobar, T. (2014). El mito del arte y el mito del pueblo: Cuestiones sobre arte popular. Buenos Aires. Ariel.

Flores, E. (1988). El concepto de "cultura estética" en Juan Acha y su relación con el de "cultura visual" de Néstor García Canclini. En Cuaderno de Publicaciones APROA (Artistas Plásticos de Rosario Agremiados) Nº 2 p. 29-37. Rosario. Universidad Nacional de Rosario.

Guasch, A. (1997). El arte del siglo XX en sus exposiciones. 1945 - 1995. Barcelona. Ediciones del Serbal.

IADAP. (1980). Conceptos operativos de diseño (Folleto N²). Quito. Instituto Andino de Artes Populares.

IADAP. (s/f). Estructura de la forma plástica. Quito. Instituto Andino de Artes Populares.

Kultermann, U. (2013). Historia de la historia del arte. Madrid. Akal.

Milla, C. (1992). Génesis de la Cultura Andina. Lima. Fondo Editorial C.A.P.

Milla, Z. (2008). Introducción a la semiótica del Diseño Andino Precolombino. Lima. Editorial Amaru Wayra.

Pérez, C., Rizzo, M. (2015). "Propuestas artísticas de las artes visuales del Ecuador desde la segunda mitad del siglo XX hasta la actualidad” en Arte, Individuo y Sociedad. 2016: 28(1) 139-154. 139. Ediciones Complutense. http://dx.doi.org/10.5209/rev_ARIS.2016. v28.n1.47715

Scheller, U. (1972). El Mundo de Los Salasacas. Guayaquil. Fundación Antropológica Ecuatoriana.

(s/f). Diseños Salasacas. Proyecto PNUD-FAO-ECU 79-007. Banco Central del Ecuador. 


\title{
Archivo audiovisual
}

Domínguez, A; Muscico, M. (2013). Tapiz Salasaca. Documental. PUCESA.

\begin{abstract}
This analysis arises from a macro research that seeks to determine how the transformations in the movements of art and design in Ecuador drove the graphic modifications in salaa art crafts during the years 1960 to 2010. It is therefore a study that seeks to understand the process of reconfiguration of the residual and dominant systems, within the framework of the Ecuadorian aesthetic culture, and how this process transfigured the formal and figurative characteristics of the crafts of this town.
\end{abstract}

Keywords: Iconography - aesthetic systems - art - crafts - design - Salasaca

Resumo: Esta análise surge de uma pesquisa macro que busca determinar como as transformações nos movimentos de arte e design no Equador impulsionaram as modificações gráficas no artesanato de salaa artísticas entre os anos de 1960 a 2010. É, portanto, um estudo que procura compreender o processo de reconfiguração dos sistemas residuais e dominantes, no marco da cultura estética equatoriana, e como esse processo transfigurou as características formais e figurativas do artesanato desta aldeia.

Palavras chave: Iconografia - sistemas estéticos - arte - artesanato - design - Salasaca

[Las traducciones de los abstracts fueron supervisadas por el autor de cada artículo] 